\title{
Defensive Behaviors of Copper-headed Trinket Snakes, Coelognathus radiatus (Boie 1827) (Squamata: Colubridae), from the Sakaerat Biosphere Reserve, Thailand
}

\author{
Bartosz Nadolski ${ }^{1}$, Krunal Trivedi ${ }^{2}$, Khan Ashaharraza ${ }^{3}$, and Pongthep Suwanwaree ${ }^{4}$ \\ ${ }^{1}$ School of Biology, Institute of Science, Suranaree University of Technology, Thailand 30000 (bartnad@gmail.com) \\ 253, Pushpak Housing Society, Palanpur patiya, Surat, Gujarat, India- 395009 (krunal.trivedi.7567@gmail.com) \\ ${ }^{3}$ Research Administrator, Indian Herpetological Society, Pune, Maharashtra, India- 411009 (elachistodon@hotmail.com) \\ ${ }^{4}$ School of Biology, Institute of Science, Suranaree University of Technology, Thailand 30000 (pongthep@sut.ac.in)
}

$\mathrm{P}$ redation pressure is a fundamental selective force for the development of traits that increase prey survival by limiting a predator's ability to detect, recognize, approach, subjugate, or consume prey (Endler 1986; Greene 1988; Lima and Dill 1990). Squamates and snakes in particular exhibit an extremely diverse array of antipredator tactics and serve as interesting models for examining evolutionary mechanisms to avoid predation (Greene 1988).

The Copper-headed Trinket Snake, Coelognathus radiatus (Boie 1827), is a non-venomous colubrid snake found in much of southeastern Asia, with a range extending from India and southern China to Myanmar, Thailand, Vietnam, Cambodia, Laos, the Malay Peninsula, Sumatra, Borneo, and Java (Das 2012). Observations of 17 adults were recorded in forested and human-altered habitats during 2015-2018 at the Sakaerat Biosphere Reserve, Nakhon Ratchasima Province, Thailand $\left(14.4933^{\circ} \mathrm{S}, 101.9219^{\circ} \mathrm{W}\right.$; datum: WGS84).

Death-feigning (also known as thanatosis, catalepsy, or tonic immobility) is expressed by maintaining a rigid posture or by simulating fully relaxed muscles (Greene 1988; Vogel and Kam Han-Yuen 2010). Death-feigning has been reported in Coelognathus radiatus (Vogel and Kam Han-Yuen 2010). Herein we describe a broader array of defensive strategies that we have observed in Copper-headed Trinket Snakes.

Whenever possible, the first response to a threat by Coelognathus radiatus is a rapid retreat. However, when unable to flee, individuals will expand the neck, exposing the contrasting light blue and black coloration of the interscale skin (Fig. 1A). If disturbed further, snakes elevate the anterior part of the body, open the mouth, and frequently feign attacks and bites (Fig. 1B). The latter are fast and energetic, apparently aimed at the face of the perceived threat. We observed one snake strike twice with such force that it lifted its entire body off the ground. Snakes displaying this behavior will stand their ground and continue to charge until they create enough space to flee.

The final defensive display, death-feigning (Fig. 1C), was observed in seven of the 17 individuals, two of which employed thanatosis after initially fleeing. In each instance, the snake rolled over and exposed its venter and relaxed the muscles in most of its body. The noteworthy exception was that snakes did not relax the muscles in the nuchal region. The connection between the skull and the vertebral column is fragile; we surmise that relaxing the muscles in that area could leave the snake vulnerable to injury if attacked by a predator.

\section{Acknowledgments}

This research was supported by Suranaree University of Technology (SUT) and by the Office of the Higher Education Commission under the NRU Project of Thailand. We also thank the Thailand Institute for Scientific and Technological Research for permission to work in the Sakaerat Environmental Research Station. Our research was carried out under the guidelines and approval of the SUT Animal Use and Ethics committee and the National Research Council of Thailand. We are grateful to S. Waengsothorn, G. Vogel, A. Khaire, S. Patel, and K. Nadolska. C. Radcliff, C.R. Smith, and J. Goodyear assisted in the field.

\section{Literature Cited}

Das, I. 2012. A Naturalist's Guide to the Snakes of South-East Asia including Myanmar, Thailand, Malaysia, Singapore, Sumatra, Borneo, Java and Bali. John Beaufoy Publishing, Oxford, UK.

Endler, J.A. 1986. Defense against predation, pp. 109-134. In: M.E. Feder and G.E. Lauder (eds.), Predator-prey Relationships: Perspectives and Approaches from the Study of Lower Vertebrates. The University of Chicago Press, Chicago, Illinois.

Greene, H.W. 1988. Antipredator mechanisms in reptiles, pp. 1-152. In: C. Gans and R.B. Huey (eds.), Biology of the Reptilia. Volume 16, Ecology B. Defense and Life History. Alan R. Liss, Inc., New York, New York. 
Lima, S.L. and L.M. Dill. 1990. Behavioral decisions made under the risk of predation: A review and prospectus. Canadian Journal of Zoology 68: 619-640.
Vogel, G. and H. Kam Han-Yuen. 2010. Death feigning behavior in three colubrid species of tropical Asia. Russian Journal of Herpetology 17: 15-21
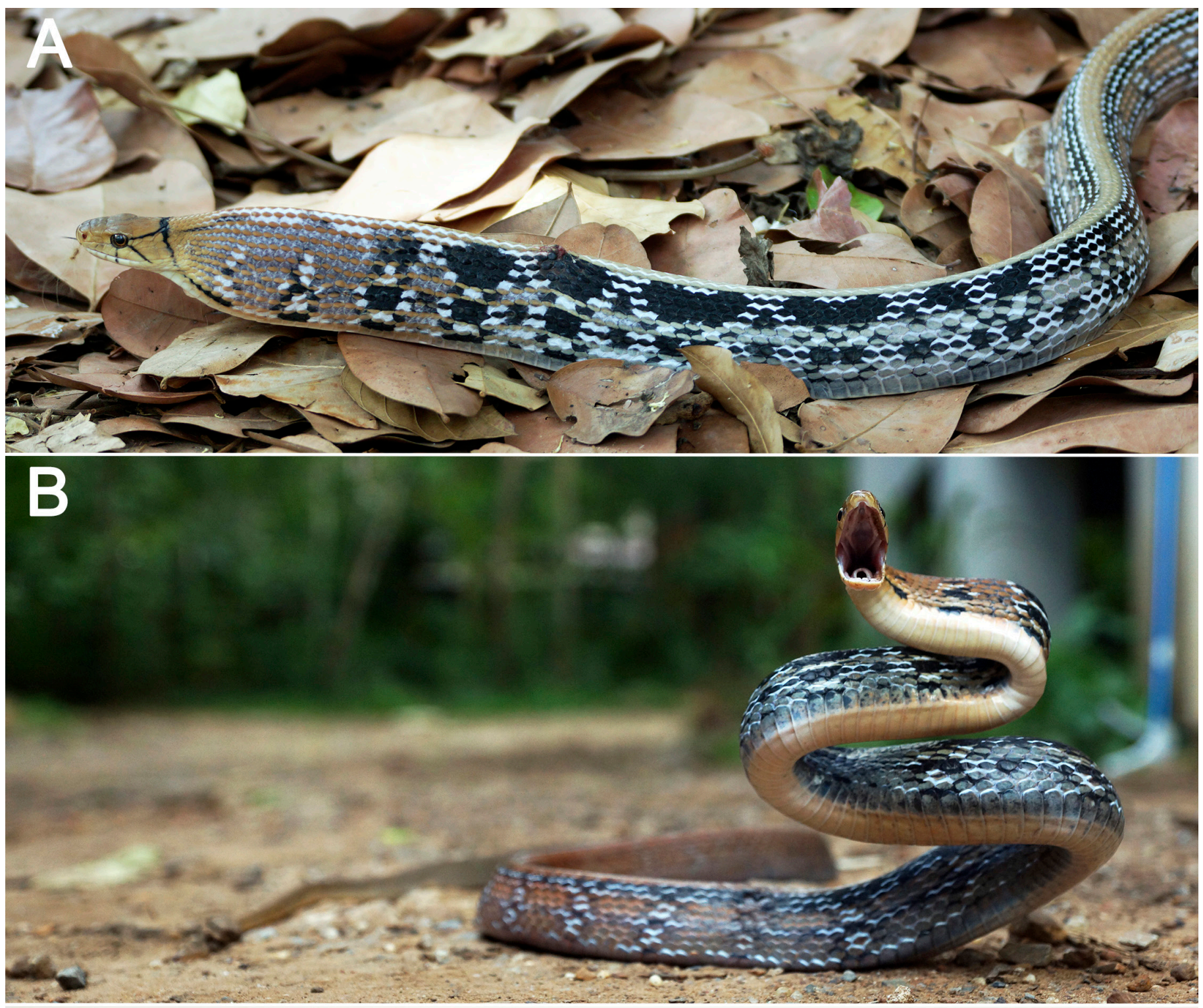

C

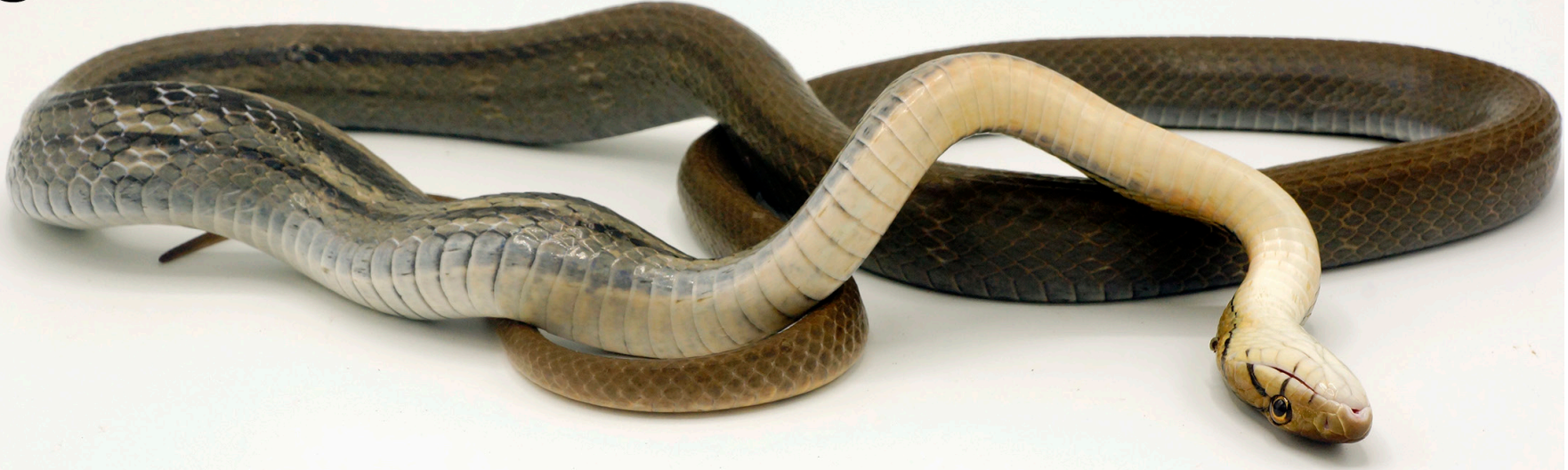

Fig. 1. Responses by Copper-headed Trinket Snakes (Coelognathus radiatus) to a threat include in order: Rapid flight; expansion of the neck to expose strongly contrasting skin colors (A); elevating the anterior body, gaping, striking, and biting (B); and death-feigning (C). Photographs by Bartosz Nadolski. 